\title{
MicroReview
}

\section{Photobiology of microorganisms: how photosensors catch a photon to initialize signalling}

\author{
Klaas J. Hellingwerf, ${ }^{*}$ Wouter D. Hoff ${ }^{\dagger}$ and \\ Wim Crielaard \\ Department of Microbiology, E.C. Slater Instituut, \\ BioCentrum Amsterdam, University of Amsterdam, \\ Nieuwe Achtergracht 127, 1018 WS Amsterdam, \\ The Netherlands.
}

\section{Summary}

Photobiological processes are relevant for microorganisms for energy generation, protection against excess and/or damaging radiation, and for signalling. In this review we give an overview of the knowledge on the functioning of photosensors in microorganisms, with special emphasis on the conformational changes that lead to signal generation and transduction. Light is absorbed by specific chromophores, which are tuned, by their proteinaceous environment, to function optimally. These chromophores belong to three classes: tetrapyrroles, polyenes and aromatics. The chemical structure of photosensing pigment/ protein complexes has been resolved for many of the photobiological processes that have a characteristic sensitivity in the visible and infrared part of the spectrum of (solar) radiation. However, knowledge about the structure of photoreceptors responsible for several physiologically well-characterized photoresponses to UV- and blue light is still lacking. For a limited number of phototransduction processes, the details of light-induced signal transfer are beginning to be understood in atomic detail. This applies particularly to two photosensors involved in phototactic responses in bacteria: sensory rhodopsin I (SR-I) from Halobacterium salinarium and photoactive yellow protein (PYP) from Ectothiorhodospira halophila. The SR-I system is of special interest because the transducer accepting the signal from SR-I was recently identified as Htr-I, a homologue of the methyl-accepting chemotaxis proteins which have

Received 1 December, 1995; revised 4 June, 1996; accepted 7 June, 1996. †Present address: Department of Microbiology and Molecular Genetics, Health Science Centre at Houston, University of Texas, Houston, Texas 77030, USA. *For correspondence. E-mail a417hell@chem.uva.nl; Tel. (20) 5257055; Fax (20) 5257056. been characterized in Escherichia coli. PYP, on the other hand, may be the first photosensor to actually reveal all relevant details of the kinetics, thermodynamics, and molecular motion of light-induced signal generation, through an understanding of how the photo-isomerization of the chromophore forces the sensor protein into the signalling state. Here we compare these photosensors and discuss common themes in the initiation of photosensory signal transduction in microorganisms in terms of the molecular properties of photosensors and their signalling state.

Light, colours, energy, signals, damage, protection and the definition of photosensors

Understanding the ability of living organisms to absorb visible photons, leading to the formation of excited molecules that are biologically relevant, is the essential issue of photobiology. This absorbance of light generally occurs through proteins, which themselves, however, do not absorb light of wavelengths greater than $300 \mathrm{~nm}$. In spite of this, a broad range of proteins display absorbance bands in the visible region of the spectrum of electromagnetic radiation (i.e. these are coloured proteins) as a result of the chromophores with which they are associated. Light absorbance by coloured proteins is not always of biological relevance (e.g. this is the case with myoglobin). Nevertheless, in several of these chromophoric proteins, electronic excitation by visible light initiates a biological response to the incoming radiation; these are called photoreceptor proteins.

Light absorbance by such photoreceptors can be associated with different biological functions. First, light can be used as an energy source for maintenance and growth: photosynthesis. Second, it can be involved in diminishing the deleterious effects of otherwise damaging radiation: photoprotection. Third, light absorbance can lead to a biologically relevant signal transfer: photosensing. The conservation of light energy in photosynthesis is discussed at length elsewhere (e.g., see Mathies, 1995).

Light can be both dangerous and harmful. Upon absorption of a visible photon by a photoactive protein, the immediate surrounding of the chromophore heats up some $200 \mathrm{~K}$ in the picosecond to microsecond time-domain (Li and Champion, 1994). This makes it easy to imagine 
that photoactive proteins are prone to damage. However, even prior to this heating, other types of damage can occur. The excited singlet- or triplet-state of many chromophores can react with molecules such as oxygen to give rise to the highly reactive superoxides. These molecules may subsequently covalently modify (and thus damage) proteins in a cell at random. In addition (near)UV radiation may cause damage, in particular to nucleic acids. Significantly, these two forms of light-induced damage of living organisms are counteracted by specific light-dependent protection- and repair mechanisms. Photolyase is classified among the latter mechanisms (e.g., see Sancar and Sancar, 1988).

The beneficial and detrimental effects of electromagnetic radiation urge many microorganisms to react specifically to their ambient light climate. This response can take various forms: cells may migrate towards or away from a particular environment, via active swimming in a phototactic process, or via vertical migration, by exploiting differences in buoyancy, and/or they may induce or repress specific (sets of) genes. Three aspects of the light climate are important in this respect: intensity, periodicity and spectral composition. Recent progress in the elucidation of new types of photoreceptors for these processes has occurred, particularly in the area of phototaxis (see below).

Thus, photosensors can be defined as proteins that neither funnel energy from light into cellular bioenergetics, nor carry out a repair function, but, as their only function, generate a signal upon light excitation. In this review, we will discuss general aspects of photoactive proteins in microorganisms, with emphasis on signal generation in photosensors.

Until recently, detailed molecular knowledge of the mechanism of photosensing was limited to the rhodopsins. One of the main focal points in this review will be the conclusions that can be drawn from a comparison of the rhodopsins with the photoactive yellow protein (PYP) of Ectothiorhodospira halophila (a halo- and alkaliphilic purple sulphur bacterium, which thrives in alkaline brines) for which a significant amount of molecular information has recently become available. PYP is a photosensor that is presumably involved in negative phototaxis in $E$. halophila (Sprenger et al., 1993). It is the first- and best-described member of a new family of photosensors (Hoff et al., 1994a,b; Koh et al., 1996; Kort et al., 1996b). Because of their function and distinct yellow colour, we propose to call this family the xanthopsins (Kort et al., 1996a).

The majority of the chromophores active in nature as photoreceptor pigments can be classified as either tetrapyrroles or polyenes (Table 1). A new type of cofactor is present in PYP: p-coumaric acid (Hoff et al., 1994a; Baca et al., 1994). With some other newly identified chromophores, such as stentorin (Tao et al., 1993), blepharismin
(Gioffré et al., 1993), flavin (Galland and Senger, 1991) and indolone (Takekuma et al., 1994), p-coumaric acid shares the chemical entity of the aromatic ring. This leads us to distinguish a third class of chromophores (see Table 1 and Fig. 1). These newly identified chromophores also raise the question of whether or not they are involved in additional eubacterial blue-light-induced photoresponses. Information is not yet available on this issue, but it is relevant in the respect that for many eubacterial blue-light photoresponses, the responsible chromophore and corresponding apoprotein remains to be elucidated, e.g. the photoreceptor that synchronizes the (cyano)bacterial circadian clock (Kondo et al., 1994).

Table 1. The chromophores relevant for photobiology.

\begin{tabular}{|c|c|}
\hline Q4ర Class & २ 4 Representatives \\
\hline \multicolumn{2}{|l|}{ Tetrapyrroles } \\
\hline & Phytochromobilin \\
\hline & (Bacterio)Chlorophyll \\
\hline & (Bacterio)Pheophytin \\
\hline \multicolumn{2}{|l|}{ Polyenes } \\
\hline & Carotene \\
\hline & Retinal \\
\hline \multicolumn{2}{|l|}{ Aromatics } \\
\hline & $p$-coumaric acid \\
\hline & stentorin \\
\hline & blepharismin \\
\hline & \begin{tabular}{|l|} 
flavin \\
\end{tabular} \\
\hline & pterin \\
\hline
\end{tabular}

Based on their chemical structure, these chromophores can be subdivided into three classes, which correlate significantly with their wavelength of maximal absorbance. Most chromophores have the basic structure of a tetrapyrrole: four covalently linked heterocyclic pyrrole rings, either in linear (e.g. phytochrome) or in circular form (e.g. (bacterio)chlorophyll). The resulting large conjugated (ring) structure in these tetrapyrroles specifically allows these chromophores to absorb photons from the red and infrared parts of the spectrum (via their so-called $Q_{Y}$ transition; these chromophores also absorb at shorter wavelengths, via their $Q_{x}$ and $Q_{z}$ transitions). The second class of chromophores has a polyene structure. Linear polyenes with approximately 10 carbon-carbon double bonds give rise to an electronic structure with p-electrons, which is optimally suited to absorb green light (approx. $500 \mathrm{~nm}$ ). Some of the polyenes, i.e. many of the carotenoids, have a very typical optical absorbance spectrum, with a main transition that shows a three-fold degeneracy as a result of vibrational fine structure. With increasing chemical derivatization at the two extreme ends of a carotenoid molecule, in particular, by means of increasing oxygenation, or by an increased conformational constraint (such as the formation of a cis-isomer), the three bands merge into one. In the rhodopsins, this effect leads to the typical asymmetric absorption band, with a side-band visible at the high-energy shoulder of the main transition, at a characteristic spacing of $30 \mathrm{~nm}$. A third, slightly heterogeneous, class then remains, which mostly contains members that can be characterized as 'bluelight'-absorbing chromophores. Most members of this class have a structure with (a) substituted aromatic ring(s) or heterocyclic rings. The most important substituent is the hydroxy group. Stentorin from Stentor coeruleus is a homocyclic member of this class, as is the chromophore of the green fluorescent protein from jellyfish. The flavins and pterins belong to the heterocyclic members of this class of chromophores. 


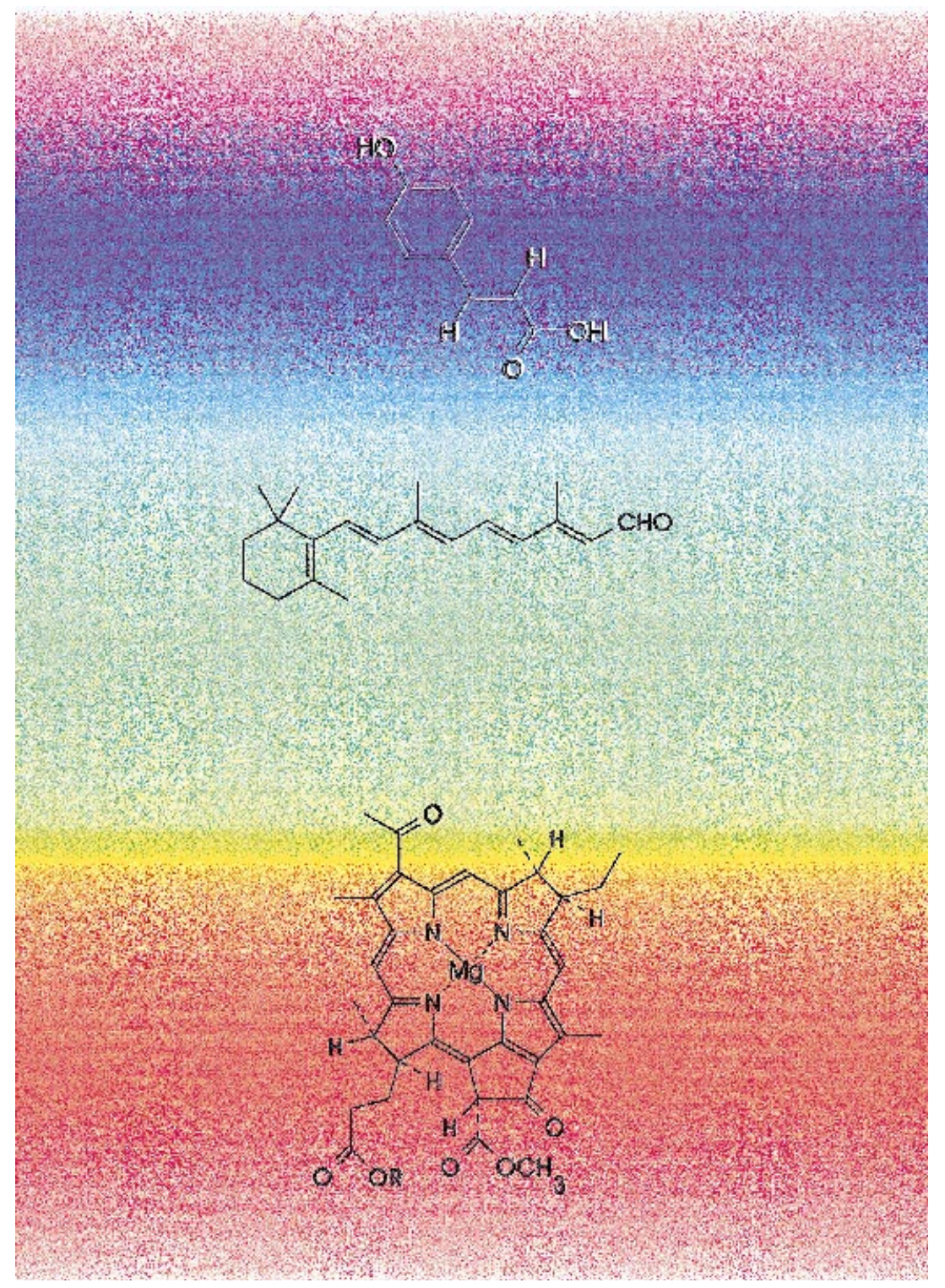

Fig. 1. Three representative chromophore structures correlated with the wavelength of their in vivo maximal absorbance, as indicated by the background colour (for further explanation, see the text). Top, p-coumaric acid. Middle, retinal.

Bottom, chlorophyll ring.

\section{Putative photoreceptors relevant for photobiology in microorganisms}

A large number of photoreceptor proteins has been described that have a function in photobiology of microorganisms. Table 2 lists the most important of these, according to their primary function. Both the structure and function of several of these have been resolved. Note that some pigments involved in photosynthesis are also involved in phototaxis responses. This particularly applies to antenna pigments, reaction centres and photosystems (which, e.g. in Rhodobacter sphaeroides and Phormidium also mediate phototactic responses in their host organism; see, e.g. Armitage, 1992; Häder, 1987) and to bacteriorhodopsin (Bibikov et al., 1993). A similar duality of function applies to yet another subsection of the phototransducers, the carotenoids of purple bacteria; these have a function in both photosensing and photoprotection (Cogdell and Frank, 1988).

Among the true photosensors, those that have a function in phototactic processes prevail. Several of these have been characterized extensively, including analysis of the structure of their chromophore and its photochemistry, which is dominated by cis/trans isomerization (see below). The evidence for the presence of phytochrome and phycochrome in cyanobacteria is preliminary; no explicit proposal has been formulated for their function. (Note, however, that phytochrome consensus sequences have recently been identified in a cyanobacterial genome sequencing project.) This is in contrast to the situation in plants, in which the key role of phytochromes in light perception is well documented (e.g. Quail, 1991). 
Table 2. Main classes of photoactive proteins from microorganisms with their chromophore(s), taxonomic distribution and photochemistry.

\begin{tabular}{|c|c|c|c|}
\hline $\begin{array}{l}\text { Photoactive protein/ } \\
\text { Photoreception process }\end{array}$ & Chromophore(s) & Taxonomic distribution & Photochemistry \\
\hline \multicolumn{4}{|l|}{ Phototransducers } \\
\hline \multicolumn{4}{|l|}{ Antenna complexes } \\
\hline Phycobiliproteins & linear tetrapyrroles & cyanobacteria \& Rhodophyta & exciton transfer \\
\hline $\begin{array}{l}\text { Light harvesting complexes } \\
\left(\mathrm{LH}_{\mathrm{I}} \text { and } \mathrm{LH}_{\mathrm{II}}\right)\end{array}$ & $\begin{array}{l}\text { bacteriochlorophyll } \\
\text { carotenoids }\end{array}$ & anoxyphotobacteria & exciton transfer \\
\hline Light-harvesting complex & chlorophyll & prochlorophyta \& algae & exciton transfer \\
\hline \multicolumn{4}{|l|}{ Reaction Centers } \\
\hline Q-type RC's & bacteriochlorophyll $^{*}$ & purple \& green bacteria & electron transfer \\
\hline P-type RC's & bacteriochlorophyll ${ }^{*}$ & green \& heliobacteria & exciton- $\&$ electron transfer \\
\hline Photosystem-II & chlorophyll ${ }^{*}$ & oxyphotobacteria \& algae & electron transfer \\
\hline Photosystem-I & chlorophyll & oxyphotobacteria \& algae & electron transfer \\
\hline \multicolumn{4}{|l|}{ Ion Pumps } \\
\hline bacterio- \& halorhodopsin & retinal & archaebacteria & cis/trans isomerization \\
\hline \multicolumn{4}{|l|}{ Photoprotection } \\
\hline DNA photolyase & $\begin{array}{l}\text { flavin } \\
\text { pterin }\end{array}$ & all three domains & exciton- \& electron transfer \\
\hline \multicolumn{4}{|l|}{ Photosensors } \\
\hline \multicolumn{4}{|l|}{ Phototaxis receptors } \\
\hline Sensory rhodopsins & retinal & archaebacteria & cis/trans isomerization \\
\hline Chlamyrhodopsin & retinal & Chlamydomonas & cis/trans isomerization? \\
\hline Photoactive yellow protein & $p$-coumaric acid & purple bacteria & cis/trans isomerization? \\
\hline Stentorin & stentorin & Stentor coeruleus & electron transfer? \\
\hline \multicolumn{4}{|l|}{ Unknown function } \\
\hline Phytochrome & phytochromobilin & green algae \& cyanobacteria & cis/trans isomerization? \\
\hline Phycochrome & linear tetrapyrrole & cyanobacteria & cis/trans isomerization? \\
\hline \multicolumn{4}{|c|}{ Presumed photoreception processes } \\
\hline \multirow[t]{2}{*}{ Algal phototaxis } & blepharismin & Blepharisma japonicum & $?$ \\
\hline & pterin? & Euglena & $?$ \\
\hline Circadian synchronization & $?$ & cyanobacteria \& algae & $?$ \\
\hline Chromatic adaptation & retinal & Calothrix sp. & cis/trans isomerization? \\
\hline Carotenoid synthesis & protoporphyrin IX & Myxococcus xanthus & $?$ \\
\hline Colony migration & $?$ & Rhodospirillum centenum & $?$ \\
\hline Microsporin synthesis & $?$ & cyanobacteria $\&$ algae & $?$ \\
\hline Pigment synthesis & $?$ & purple bacteria & $?$ \\
\hline Spore development & mycochrome? & fungi & $?$ \\
\hline Photosynthesis? & indolone & $\begin{array}{l}\text { Pleurotus } \\
\text { salmoneostramineus }\end{array}$ & $?$ \\
\hline
\end{tabular}

Recently, a gene homologous to HY4 has been identified in Chlamydomonas (Small et al., 1995). In Arabidopsis thaliana, the product of this gene is involved in blue-light reception for hypocotyl elongation, and its amino acid sequence shows considerable homology with photolyases (Ahmad and Cashmore, 1993). These homologies may contribute to the understanding of the structure and function of their prokaryotic counterparts. In this respect, it is relevant to note that the photochemistry of photolyases is based upon light-induced reversible electron transfer (see e.g. Kim et al., 1992). The HY4 homologue might have a function in the sexual interactions between Chlamydomonas cells.

Many more light-dependent responses have only been partially characterized in microorganisms. The most important of these have been listed in the lower part of Table 2. Many of these responses have a function in light-induced regulation of gene expression; however, a phototaxis process in Rhodospirillum centenum is also included (Ragatz et al., 1995). For some of these (such as blepharismin; Tao et al., 1993), indications about the structure of the chromophore involved have been obtained through extensive physiological characterization. For others, neither the chromophore, nor the corresponding apo-protein is known. With the powerful methods of molecular genetics and analytical chemistry, it is hopeful that this information will become available in the near future.

Eukaryotic microorganisms, in particular, display a range of responses towards light, with highest sensitivity in the blue part of the visible spectrum (see e.g. Senger, 1980; 
1984; 1987; Ninnemann, 1980). This has been called the 'blue light syndrome', with the corresponding term 'cryptochrome' used for the chromophore(s) involved. However, despite intense research, the nature of most of the bluelight receptors involved is unknown. Carotenoids and flavins (see e.g. Galland and Senger, 1991) have traditionally been proposed as being the most likely of the candidate chromophores to be responsible for these blue-light effects. The recent characterization of several aromatic chromophores (see Table 1 and Fig. 1) also makes these serious candidates for being the 'cryptochrome'.

In yet another form, light plays an important role in biology, i.e. light is emitted by a multitude of (micro)organisms. These bioluminescent proteins (like luciferase and green fluorescent protein) have been omitted from Table 2 . It is, nevertheless, striking to note how the aromatic chromophores also abound in the bioluminescent proteins.

Although many processes have been identified as being regulated by light (see Table 2), relatively few have been characterized in so much detail that an actual photosensor has been identified. For most, characterization has not proceeded beyond the documentation of an action spectrum. Only in those examples where it has been possible to combine spectroscopic data with biochemistry and molecular biology (e.g. with the sensory rhodopsins and photoactive yellow protein) has more detailed information become available.

Information about the three-dimensional structure of photosensors is very scarce. For those, except PYP (see below), for which it is available, it has been obtained through combining various techniques from biochemistry, electron microscopy, spectroscopy and modelling. Models for the signal-transducing rhodopsins have profited from the detailed information available for bacteriorhodopsin (Henderson et al., 1990). Studies on the photoactive yellow protein have evolved via an almost reverse path. The first indication for the presence of a photosensor in E. halophila became available upon the isolation of a yellow-coloured photoactive protein (PYP; Meyer, 1985; Meyer et al., 1987). Even before the function of this protein became apparent, a three-dimensional structure, at $2.4 \AA$ resolution, was published. The spectroscopic characteristics of this protein showed both absorbance and photocycle kinetics reminiscent of retinal proteins (Meyer et al., 1987; 1991; Hoff et al., 1992; 1994c). However, the fact that it was impossible to extract retinal, either from the cells or from the isolated protein, suggested basic structural differences between PYP and the rhodopsins (Van Beeumen et al., 1993). Recently, the initially published structure of PYP was reported to be erroneous, and replaced by a structure at $1.4 \AA$ resolution (Borgstahl et al., 1995).

As a result of detailed phototaxis studies in E. halophila, a new type of eubacterial phototaxis (negative phototaxis in a free-swimming Eubacterium) was revealed, with an action spectrum which matches the spectrum of PYP, thereby linking the photosensor to a cellular response (Sprenger et al., 1993). Finally, by using a large array of techniques, the nature of the chromophore of PYP, $p$-coumaric acid, could also be established (see above). By using reverse genetics it has been possible to isolate the gene encoding the apoPYP, which now allows the use of molecular biological techniques to further study yellow proteins. This, up to now, has not only led to the conclusion that several other Eubacteria also contain a PYP, but also led to a proposal for the mechanism that is used in vivo to covalently attach the chromophore via (an unusual) thioester-linkage to the apoprotein, via a coumaryl-CoA ligase (Kort et al., 1996a). Reconstitution studies, in which p-coumaric acid is reintroduced in the protein, have recently been performed in vitro, both with $p$-coumaric acid (Imamoto et al., 1995; Kort et al., 1996a) and with several of its analogues (A. Kroon, unpublished observations). These recent advances in knowledge of PYP make this photosensor the best candidate for understanding initiation of photosignalling at full atomic resolution.

\section{The general structure of sensory photocycles}

Photosensing is initiated through the absorption of a photon by a protein-bound chromophore and the resulting photochemical conversion of this chromophore. The chromophores of photoactive proteins generally have an extinction coefficient in the order of $10^{4} \mathrm{mM}^{-1} \mathrm{~cm}^{-1}$. This is caused by the presence of a system of conjugated $\pi$ orbitals in all three basic types of chromophores (Fig. 1).

Classification of the photochemistry of the reactions that are relevant for photobiology is very straightforward. Lightabsorption induces either: (i) excitation transfer, (ii) electron transfer, or (iii) photoisomerization. Representatives of all three classes of chromophores (Table 1), in some form or another, can display all three types of photochemistry, except for light-induced electron transfer, which is not found among the polyenes. (Note, however, that for some photobiological processes, light-induced $\mathrm{H}^{+}$-transfer is considered as a or perhaps the primary event.)

Photobiological processes generally function with a high quantum yield, often near unity. This is true for all three types of photochemical reaction: excitation transfer, electron transfer, and photoisomerization. This latter type of reaction in organic chemistry mostly has a quantum yield that is far smaller than that occurring in photobiological processes. The explanation for this must lie in the apoprotein surroundings of the chromophores.

In all three types of photosensory protein for which detailed molecular information is available (rhodopsin, phytochrome, and PYP), light-induced cis-trans isomerization forms the photochemical basis of signal generation. 


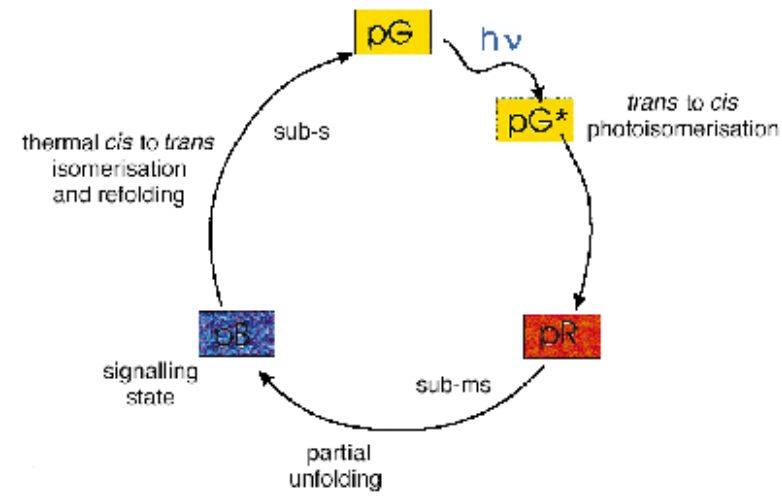

Fig. 2. A prototype photocycle of a (bacterial) photosensor. G, groundstate; R, short-living red-shifted intermediate; $B$, longliving blue-shifted intermediate, which is presumably the signalling state of the photosensor. Characteristic order-of-magnitude transition times have been indicated.

In the case of stentorin, however, preliminary evidence indicates that proton and/or electron transfer is involved. For proteins with a photochemical cycle, in which the initial state i.e. groundstate $(G)$ of the protein is recovered on the (sub)second timescale (i.e. PYP and sensory rhodopsin $(\mathrm{SR})$ ), the primary photointermediate $(\mathrm{R})$ displays a redshifted absorbance spectrum. On a sub-millisecond timescale this $R$ intermediate is converted to a blue-shifted state $(B)$, concomitant with a significant change in protein conformation (see below); this gives rise to the (proposed) signalling state of the photoreceptor, which leads to a biological response (Fig. 2). In the slowest step of the photocycle, the groundstate of the receptor is recovered after thermal chromophore re-isomerization and protein conformational relaxation to the groundstate. The similarity between the archaeal sensory rhodopsins and PYP in this respect (Spudich and Bogomolni, 1988; Marwan and Oesterhelt, 1990; Meyer et al., 1987; Hoff et al., 1994c, 1996) is a surprise, because the structures of both the chromophore and the protein part of these photosensors are strikingly different (see above).

We propose the following explanation for these similarities between the sensory rhodopsins and PYP. In the initial- or groundstate of the protein, the chromophore is caged in a highly constrained binding pocket, leading to spectral tuning of the absorbance band of the protein. The photo-isomerization of the chromophore to its signal-relaying conformation (from trans to cis in both the archaeal sensory rhodopsins (Tsuda et al., 1985; Yan et al., 1990) and also in PYP (Kort et al., 1996b)) occurs on a time-scale that is too short for the protein structure to relax significantly to accommodate this new chromophore conformation. Thus, the cis isomer of the chromophore is, transiently, highly distorted by the tuning pocket of the protein, which is designed for the trans isomer (for further details, see Mathies et al., 1991; Yan et al., 1993). This leads to a red-shift in its absorbance band.

The distortion of the chromophore causes a relatively large fraction of the energy of the photon to be stored in the first, red-shifted intermediate: $80 \%$ in the case of bacteriorhodopsin, and $50 \%$ in the case of PYP (Rohr et al., 1992; Van Brederode et al., 1995). This conformational strain is the driving force for the next step in the photocycle i.e. the structural relaxation of the protein away from its groundstate to a state of the protein that is more compatible with the cis conformation of the chromophore. For SR-I it has been shown that the 13-methyl group of retinal acts as a steric trigger for the protein conformational changes, leading to receptor activation (Yan et al., 1991a); in the case of vertebrate-eye rhodopsins the 9methyl group performs a similar function (Ganter et al., 1989). During this conformational change, the spectral tuning pocket is lost, leading to a shift in pK of important functional groups of the chromophore (see below) and a loss of chromophore tuning. This results in a blue-shift in the absorbance spectrum of the chromophore, close to the position that is observed for model compounds of the chromophore in solution. In general, the magnitude of this shift is not directly biologically relevant, since of the blue-shifted intermediate the signal relaying conformation, but not the colour, is crucial (see below). For SR-I, however, this blue-shifted intermediate itself is also involved in photosensing (Spudich and Bogomolni, 1984).

The signalling state is by far the most stable intermediate in the photocycle. This is biologically relevant, because it allows the photosensor in its signalling state to interact with its transducer, i.e. the second component of the signal-transduction chain. The lifetime of the signalling state can be evolutionarily tuned for any photosensor by modifying the degree of catalysis of the thermal re-isomerization of the chromophore back to the groundstate (trans) conformation.

Both the formation of a blue-shifted signalling state and the reformation of the groundstate may involve additional (red-shifted) intermediates. This does not affect the description given above, which leads to a unified view on sensory photocycles, summarized in Fig. 2.

\section{Protein-chromophore interactions}

\section{Spectral tuning}

A dramatic red-shift of its absorbance band often occurs upon binding of a chromophore to its photosensor apoprotein. Considerable attention has been paid to understanding the physical basis for this shift: the 'spectral tuning problem'. Spectral tuning in the rhodopsins can be defined as the spectral shift (see Nakanishi et al., 1980) from $367 \mathrm{~nm}$ (the wavelength is slightly dependent on the 
solvent used) for retinal in solution to $587 \mathrm{~nm}$ in the case of SR-I, and $487 \mathrm{~nm}$ in the case of SR-II. For PYP, tuning occurs from $284 \mathrm{~nm}$ for the free chromophore in solution at neutral $\mathrm{pH}$ to $446 \mathrm{~nm}$ in the native protein. Three different types of contribution to this tuning can be distinguished. (i) The chromophore is chemically modified as a result of covalent binding to the apoprotein. In the case of the rhodopsins, this entails the formation of a Schiffbase linkage between retinal and a lysine residue. In methanol, this Schiff-base formation causes only a minor spectral shift (to the blue: $356 \mathrm{~nm}$; Koyama et al., 1991). (ii) Already at neutral $\mathrm{pH}$, protonation of this Schiff-base occurs, owing to a strong shift in its pK, from 7.0 in solution, to 10.6 in octopus rhodopsin (Koutalos et al., 1990) and 13.2 in bacteriorhodopsin (Druckmann et al., 1982; Sheves et al., 1986), caused by the protein environment. The protonated Schiff-base absorbs at $440 \mathrm{~nm}$, so that the first two tuning factors explain approximately one half of the total shift (on the energy scale). A highly analogous situation is encountered in PYP (Baca et al., 1994; Hoff et al., 1994a). First, the p-coumaric acid chromophore is linked to the protein via a thiol ester, resulting in an absorbance shift from 284 to $335 \mathrm{~nm}$, as is typical for this class of compounds (Racker, 1951). Second, the pK of the chromophoric hydroxyl group strongly shifts, leading to its deprotonation; this explains a red-shift to $410 \mathrm{~nm}$. The molecular basis for this $\mathrm{pK}$ shift is the stabilization of the phenolate anion by the nearby and positively charged Arg-52, in combination with a hydrogen-bond network between this anion and a tyrosine, glutamate and threonine of the apoprotein (Borgstahl et al., 1995; Kim et al., 1995). (iii) The third contribution to chromophore spectral tuning involves the physical environment of the chromophore, not its chemical structure per se. For SR-I, a shift from 440 to $587 \mathrm{~nm}$ remains to be explained, while in PYP, this gap is between 410 and $446 \mathrm{~nm}$. As this aspect has been studied extensively for bacteriorhodopsin, we will briefly discuss the contributions to this aspect of tuning from 440 to $570 \mathrm{~nm}$ for this latter protein (Mathies et al., 1991). First, an increased distance between the protonated Schiff-base with its counterion(s) in the protein (probably several charged groups; see, e.g. Nakanishi et al., 1980) results in a red-shift of the absorbance band. Second, the single bond between the retinal carbon atoms 6 and 7 is forced into the s-trans conformation by the protein environment. This results in an elongation of the conjugated system of the chromophore. The third contribution comes from the interaction of protein dipoles and/or polar groups with the 5-6 double bond in the $\beta$ ionone ring and with the polyene chain of retinal (Yan et al., 1995).

As indicated above for PYP, the tuning from 410 to $446 \mathrm{~nm}$ has not yet been explained. We propose here that the high polarizability, and thus high sensitivity to static electric fields within the protein, of the phenolate anion is central to this shift. Arg-52, which is positioned close to the aromatic ring of the chromophore, may be of great importance in this respect, by forming a counterion for the charge that is delocalized from the deprotonated oxygen to the conjugated chromophore ring. Using the same terminology as used for bacteriorhodopsin, Arg-52 functions as the phenolate-anion counterion in PYP. The validity of this proposal remains to be established; strain imposed by the apoprotein on the chromophore may also contribute to this shift.

\section{Light-induced changes in the conformation of photoactive proteins: the signalling state}

Protein conformational changes are crucial both for signal generation in a (photo)receptor protein, and for signal relay in a signal transduction chain, and involve three types of processes: (i) ligand-protein interactions, (ii) covalent protein modification (e.g. phosphorylation or methylation), and (iii) protein-protein interactions.

Two important recent developments in this respect are (i) the characterization of the ligand-induced conformational changes in the extracellular domain of the chemotactic receptor Tar from Escherichia coli by X-ray crystallography and nuclear magnetic resonance (NMR) spectroscopy (Biemann and Koshland, 1994; Danielson et al., 1994; Kim, 1994), and (ii) the phosphorylationinduced conformational changes in the signal-transduction protein CheY by NMR spectroscopy (Drake et al., 1993; see also Welch et al., 1994). However, since both examples do not involve photoreceptors, they will not be further discussed here.

In the case of photoreceptors, the ligand-protein interactions involve interactions between the photo-isomerised chromophore and the apo-protein. The nature of the conformational changes in photoreceptors has been studied in some detail for SR-I and SR-II (Yan et al., 1991a,b), plant phytochromes (Wells et al., 1994; Yamamoto, 1993; Mizutani et al., 1993), animal rhodopsins (Toossi et al., 1993; Resek et al., 1993; Rath et al., 1993), and PYP. The latter protein is unique in this respect, because it has been reported that heat-capacity changes occur during its photocycle, indicating partial protein unfolding (Hoff, 1995, Hoff et al., 1995; Van Brederode et al., 1996). This indicates a new molecular basis for receptorsignal generation: (un)folding processes. An important aspect of the activation of SR-I has been identified as the 13-methyl group of the retinal molecule, which acts as a steric trigger in protein-chromophore interactions upon photo-isomerization of the retinal molecule (Yan et al., 1991a). However, the structure of the signalling state of a photo-receptor has not, even in a single case, been fully characterized yet. 


\section{How to pass on the signal}

Although some photoreceptors use light directly to activate a catalytic function, it is clear that the major part of the information acquired by the photosensors must be transmitted to a cellular response via (a series of) transducer proteins. This is clearly illustrated by the well-studied process of (photo)taxis. Since the identification of $\mathrm{Hrtl}$ in Halobacterium salinarium (which shows similarities to the so-called methyl-accepting chemotaxis proteins (MCPs); Spudich et al., 1989), evidence has been accumulating which indicates that many taxis responses in bacteria are controlled by processes similar to the wellstudied chemotaxis process in E. coli (e.g. Ward et al., 1995). In this archaetypical bacterial signal-transduction process, MCPs have the role of sensors. As is the case with photoreceptors, the inducing signal (in this case not a photon, but binding of the signalling molecule to an MCP) results in a conformational change of the sensor protein, which subsequently, through protein-protein interactions, must lead to the transduction of the signal into the cytoplasm. In the cytoplasm the signal is then relayed into a two-component regulatory system (TCRS), consisting of the histidine-kinase CheA, and the response regulators $\mathrm{CheB}$ (which has a function in adaptation) and CheY. The phosphorylation, and thus activation, of such regulators is also an intrinsic step in photosensing. CheY can interact with the bacterial flagellar motor. Corresponding components have now also been demonstrated in Halobacterium (Rudolph and Oesterhelt, 1995). In this way, the CheY phosphorylation level regulates the direction of rotation of the cell's flagella (for further details see Armitage, 1992).

\section{Outlook}

A hypothesis is emerging for a mechanism of bacterial photosensing which is based on specific photoreceptors and involves a relatively simple, four-step process. (i) Photo-isomerization of the chromophore results in (ii) a change in protein conformation (the signalling state of the protein). This is (iii) the stimulus for auto-phosphorylation of the sensor component of a TCRS, and hence induces a phospho-relay, which, finally, (iv) results in an effect exerted by the response-regulator component of the TCRS.

Although it is clear that protein conformational changes are essential in signal generation after absorbance of a photon, it has not yet been possible to resolve the spatial structure of the signalling state of any photoreceptor. Because of its small size, its water solubility, and the availability of a $1.4 \AA$ crystal structure, PYP shows great potential for changing this situation in the near future. Such results may come from X-ray diffraction studies, either time-resolved ( $\mathrm{Ng}$ et al., 1993), or through the static structure of the signalling state by either $\mathrm{X}$-ray diffraction or NMR analysis. Furthermore, the resolution of the three-dimensional structure of the groundstate of PYP with ${ }^{1} \mathrm{H}$ - and ${ }^{15} \mathrm{~N}-\mathrm{NMR}$, which is in progress ( $\mathrm{P}$. Düx unpublished data), will greatly facilitate the characterization of the three-dimensional structure of the signalling state of PYP using NMR techniques. Once the conformational transitions that are required to form a signalling state have been determined for the photoactive proteins SR-I and PYP, a large body of data will be available to generate a dynamic picture of the transitions in these receptors, incorporating structural, kinetic and thermodynamic data.

The next major challenge in signalling research will be to understand, in quantitative terms, how the conformational changes in a sensor protein are relayed into its corresponding signal-transduction chain. For this, it is of utmost importance (i) to identify the transducer of PYP, and (ii) to obtain crystals of the SR-I/Htrl complex that can be used for high-resolution structural studies.

\section{References}

Ahmad, M., and Cashmore, A.R. (1993) HY 4 gene of $A$. thaliana encodes a protein with characteristics of a bluelight photoreceptor. Nature 366: 162-166.

Armitage, J.P. (1992) Behavioral responses in bacteria. Annu Rev Physiol 54: 683-714.

Baca, M., Borgstahl, G.E.O., Boissinot, M., Burke, P.M., Williams, W.R., Slater, K.A., and Getzoff, E.D. (1994) Complete chemical structure of photoactive yellow protein: novel thioester-linked 4-hydroxycinnamyl chromophore and photocycle chemistry. Biochemistry 33: 14369-14377.

Bibikov, S.I., Grishinan, R.N., Kaulen, A.D., Marwan, W., Oesterhelt, D., and Skulachev, V.P. (1993) Bacteriorhodopsin is involved in halobacterial photoreception. Proc Natl Acad Sci USA 90: 9446-9450.

Biemann, H.-P., and Koshland, D.E. (1994) Aspartate receptors of Escherichia coli and Salmonella typhimurium bind ligand with negative and half-of-the-sites cooperativity. Biochemistry 33: 629-634.

Borgstahl, G.E.O., Williams, D.R., and Getzoff, E.D. (1995) $1.4 \AA$ structure of photoactive yellow protein, a cytosolic photoreceptor: unusual fold, active site, and chromophore. Biochemistry 34: 6278-6287.

Cogdell, R.J., and Frank, H.A. (1988) How carotenoids function in photosynthetic bacteria. Biochim Biophys Acta 895: 63-79.

Danielson, M.A., Biemann, H.-P., Koshland, D.E., and Falke, J.J. (1994) Attractant- and disulfide-induced conformational changes in the ligand binding domain of the chemotaxis aspartate receptor: a ${ }^{19} \mathrm{~F}$ NMR study. Biochemistry 33: 6100-6109.

Drake, S.K., Bourret, R.B., Luck, L.A., Simon, M.I., and Falke, J.J. (1993) Activation of the phosphosignalling protein Che $Y$. 1. Analysis of the phosphorylated conformation by ${ }^{19} \mathrm{~F} \mathrm{NMR}$ and protein engineering. $\mathrm{J} \mathrm{Biol}$ Chem 268: 13081-13088. 
Druckmann, S., Ottolenghi, M., Pande, J., and Callender, R.H. (1982) Acid-base equilibrium of the Schiff base in bacteriorhodopsin. Biochemistry 21: 4953-4959.

Galland, P., and Senger, H. (1991) In Photoreceptor evolution and function. Holmes, M.G. (ed.). London: Academic Press, pp. 65-124.

Ganter, G.U.M., Schmid, E.D., Perez-Sala, D., Rando, R.R, and Siebert, F. (1989) Removal of the 9-methyl group of retinal inhibits signal transduction in the visual process. A fourier transform infrared and biochemical investigation. Biochemistry 28: 5954-5962.

Gioffré, D., Ghetti, F., Lenci, F., Paradiso, C., Dai, R., and Song, P.-S. (1993) Isolation and characterization of the presumed photoreceptor protein of Blepharisma japonicum. Photochem Photobiol 58: 275-279.

Häder, D.-P. (1987) Photosensory behavior in prokaryotes. Microbiol Rev 51: 1-21.

Henderson, R., Baldwin, J.M., Ceska, T.A., Zemlin, F., Beckmann, E., and Downing, K.H. (1990) Model for the structure of bacteriorhodopsin based on high-resolution electron cryo-microscopy. J Mol Biol 213: 899-929.

Hoff, W.D. (1995) Photoactive yellow protein, a new family of eubacterial blue-light photoreceptors. PhD thesis, University of Amsterdam, Amsterdam, The Netherlands.

Hoff, W.D., Kwa, S.L.S., Van Grondelle, R., and Hellingwerf, K.J. (1992) Low temperature absorbance and fluorescence spectroscopy of the photoactive yellow protein from Ectothiorhodospira halophila. Photochem Photobiol 56: 529539.

Hoff, W.D., Düx, P., Hård, K., Devreese, B., NugterenRoodzant, I.M., Crielaard, W., Boelens, R., Kaptein, R., Van Beeumen, J., and Hellingwerf, K.J. (1994a) Thiol ester-linked $p$-coumaric acid as a new photoactive prosthetic group in a protein with rhodopsin-like photochemistry. Biochemistry 33: 13959-13962.

Hoff, W.D., Sprenger, W.W., Postma, P.W., Meyer, T.E., Veenhuis, M., Leguijt, T., and Hellingwerf, K.J. (1994b) The photoactive yellow protein from Ectothiorhodospira halophila as studied with a highly specific polyclonal antiserum: (intra)cellular localization, regulation of expression, and taxonomic distribution of cross-reacting protein. $J$ Bacteriol 176: 3920-3927.

Hoff, W.D., Van Stokkum, I.H.M., Van Ramesdonk, H.J., Van Brederode, M.E., Brouwer, A.M., Fitch, J.C., Meyer, T.E., Van Grondelle, R., and Hellingwerf, K.J. (1994c) Measurement and global analysis of the absorbance changes in the photocycle of the photoactive yellow protein from Ectothiorhodospira halophila. Biophys J 67: 1691-1705.

Hoff, W.D., Matthijs, H.C.P., Schubert, H., Crielaard, W., and Hellingwerf, K.J. (1995) Rhodopsin(s) in eubacteria. Biophys Chem 56: 193-199.

Hoff, W.D., Devreese, B.V., Fokkens, R., Nugteren-Roodzant, I.M., Van Beeumen, J.J., Nibbering, N., and Hellingwerf, K.J. (1996) Chemical reactivity and spectroscopy of the thiol ester-linked $p$-coumaric acid chromophore in the photoactive yellow protein from Ectothiorhodospira halophila. Biochemistry 35: 12741281.

Imamoto, Y., Ito, T., Kataoka, M., and Tokunaga, F. (1995) Reconstitution photoactive yellow protein from apoprotein and p-coumaric acid derivates. FEBS Lett 374: 157-160.
Kim, M., Mathies, R.A., Hoff, W.D., and Hellingwerf, K.J. (1995) Resonance Raman evidence that the thioesterlinked chromophore of photoactive yellow protein is deprotonated. Biochemistry 34: 12669-12672.

Kim, S.-H. (1994) 'Frozen' dynamic dimer model for transmembrane signaling in bacterial chemotaxis receptors. Protein Sci 3: 159-165.

Kim, S.-T., Li, Y.F., and Sancar, A. (1992) The third chromophore of DNA photolyase: Trp-277 of Escherichia coli DNA photolyase repairs thymine dimers by direct electron transfer. Proc Natl Acad Sci USA 89: 900-904.

Koh, M., Van Driessche, G., Samyn, B., Hoff, W.D., Meyer, T.E., Cusanovich, M.A., and Van Beeumen, J.J. (1996) Sequence evidence for strong conservation of the photoactive yellow proteins from the halophilic phototrophic bacteria Chromatium salexigens and Rhodospinillium salexigens. Biochemistry 35: 2526-2534.

Kondo, T., Tsinoremas, N.F., Golden, S.S., Johnson, C.H., Kutsuna, S., and Ishiura, M. (1994) Circadian clock mutants of cyanobacteria. Science 266: 1233-1236.

Kort, R., Hoff, W.D., Van West, M., Kroon, A.R., Hoffer, S.M., Vlieg, K.H., Crielaard, W., Van Beeumen, J.J., and Hellingwerf, K.J. (1996a) The Xanthopsins: a new familiy of eubacterial blue-light photoreceptors. EMBO $J$ 15: 3209-3218.

Kort, R., Vonk, H., Xu, X., Hoff, W.D., Crielaard, W., and Hellingwerf, K.J. (1996b) Evidence for trans-cis isomerization of the $p$-coumaric acid chromophore as the photochemical basis of the photocycle of photoactive yellow protein. FEBS Lett 382: 73-78.

Koutalos, Y. Ebrey, T.G., Gilson, H.R., and Honig, B. (1990) Octopus photoreceptor membranes. Surface charge density and pK of the Schiff base of the pigments. Biophys $J$ 58: 493-501.

Koyama, Y., Kubo, K., Komori, M., Yasuda, H., and Mukai, Y. (1991) Effect of protonation on the isomerization properties of $n$-butylamine Schiff base of isomeric retinal as revealed by direct HPLC analyses: selection of isomerization pathways by retinal proteins. Photochem Photobiol 54: 433-443.

$\mathrm{Li}$, P., and Champion, P.M. (1994) Investigations of the thermal response of laser excited biomolecules. Biophys $J$ 66: 430-436.

Marwan, W., and Oesterhelt, D. (1990) Quantitation of photochromism of sensory rhodopsin-I by computerized tracking of Halobacterium halobium cells. J Mol Biol 215: 277-285.

Mathies, P. (1995) Photosynthesis: from Light to Biosphere. Dordrecht: Kluwer Academic Publishers.

Mathies, R.A., Lin, S.W., Ames, J.B., and Pollard, W.T. (1991) From femtoseconds to biology: mechanism of bacteriorhodopsin's light-driven proton pump. Annu Rev Biophys Chem 20: 491-518.

Meyer, T.E. (1985) Isolation and characterization of soluble cytochromes, ferredoxins and other chromophoric proteins from the halophilic phototrophic bacterium Ectothiorhodospira halophila. Biochim Biophys Acta 806: 175-183.

Meyer, T.E., Yakali, E., Cusanovich, M.A., and Tollin, G. (1987) Properties of a water-soluble, yellow protein isolated from a halophilic phototrophic bacterium that has photochemical activity analogous to sensory rhodopsin. Biochemistry 26: 418-423. 
Meyer, T.E., Tollin, G., Causgrove, T.P., Cheng, P., and Blankenschip, R.E. (1991) Picosecond decay kinetics and quantum yield of fluorescence of the photoactive yellow protein from the halophilic purple phototrophic bacterium, Ectothiorhodospira halophila. Biophys J 59: 988-991.

Mizutani, Y., Tokutomi, S., Kaminaka, S., and Kitagawa, T. (1993) Ultraviolet resonance raman spectra of pea intact, large, and small phytochromes: differences in molecular topography of red-and far-red-absorbing forms. Biochemistry 32: 6916-6922.

Nakanishi, K., Balogh-Nair, V., Arnaboldi, M., Tsujimoto, K., and Honig, B. (1980) An external point-charge model for bacteriorhodopsin to account for its purple colour. J Am Chem Soc 102: 7945-7947.

Ng, K., Ren, Z., Moffat, K., Borgstahl, G.E.O., McRee, D.E., and Getzoff, E.D. (1993) Time-resolved photochemical studies of photoactive yellow protein (PYP) crystals. Biophys J 64: A373.

Ninnemann, H. (1980) Blue-light photoreceptors. Bioscience 30: $166-170$.

Quail, P.H. (1991) Phytochrome: a light-activated molecular switch that regulates plant gene expression. Annu Rev Genet 25: 389-409.

Racker, E. (1951) The mechanism of action of glyoxalase. $J$ Biol Chem 190: 685-696.

Ragatz, L., Jiang, Z.-Y., Bauer, C.E., and Gest, H. (1995) Macroscopic phototactic behavior of the purple photosynthetic bacterium Rhodospirillum centenum. Arch Microbiol 163: 1-6.

Rath, P., DeCaluwé, L.L.J., Bovee-Geurts, P.H.M., DeGrip, W.J., and Rothschild, K.J. (1993) Fourier transform infrared difference spectroscopy of rhodopsin mutants: light activation of rhodopsin causes hydrogen-binding change in residue aspartic acid-83 during Meta II formation. Biochemistry 32: 10277-10282.

Resek, J.F., Farahbakhsh, Z.T., Hubbell, W.L., and Khorana, H.G. (1993) Formation of the Meta II photointermediate is accompanied by conformational changes in the cytoplasmic surface of rhodopsin. Biochemistry 32: 1202512032.

Rohr, M., Gärtner, W., Schweitzer, G., Holzwarth, A.R., and Braslavsky, S.E. (1992) Quantum yields of the photochromic equilibrium between Bacteriorhodopsin and its Bathointermediate K. Femto- and nanosecond optoacoustic spectroscopy. J Phys Chem 96: 6055-6061.

Rudolph, J., and Oesterhelt, D. (1995) Chemotaxis and phototaxis require a CheA histidine kinase in the archaeon Halobacterium salinarium. EMBO J 14: 667-673.

Sancar, A., and Sancar, G.B. (1988) DNA repair enzymes. Annu Rev Biochem 57: 29-67.

Senger, H. (1980) The Blue Light Syndrome. Berlin: Springer-Verlag.

Senger, H. (1984) Blue Light Effects in Biological Systems. Berlin: Springer-Verlag.

Senger, H. (1987) Blue Light Responses: Phenomena and Occurrence in Plants and Microorganisms. Boca Raton, Florida: CRC Press.

Sheves, M., Albeck, A., Friedman, N., and Ottolenghi, M. (1986) Controlling the $\mathrm{pK}_{\mathrm{a}}$ of the bacteriorhodopsin Schiff base by use of artificial retinal analogous. Proc Natl Acad Sci USA 83: 3262-3266.
Small, G.D., Min, B., and Lefebre, P.A. (1995) Characterization of a Chlamydomonas reinhardtii gene encoding a protein of the DNA photolyase-blue light photoreceptor family. Plant Mol Biol 28: 443-454.

Sprenger, W.W., Hoff, W.D., Armitage, J.P., and Hellingwerf, K.J. (1993) Ectothiorhodospira halophila is negatively photoactive, with a wavelength dependence that fits the absorbance spectrum of the photoactive yellow protein. $J$ Bacteriol 175: 3096-3104.

Spudich, E.N., Takahashi, T., and Spudich, J.L. (1989) Sensory rhodopsin I and II modulate a methylation/ demethylation system in Halobacterium halobium. Proc Natl Acad Sci USA 86: 7746-7750.

Spudich, J.L., and Bogomolni, R.A. (1984) Mechanism of colour discrimination by a bacterial sensory rhodopsin. Nature 312: 509-513.

Spudich, J.L., and Bogomolni, R.A. (1988) Sensory rhodopsins of Halobacteria. Annu Rev Biophys Chem 17: 193215.

Takekuma, S.-I., Takekuma, H., Matsubaru, Y., Inaba, K., and Yoshida, Z.-I. (1994) A novel mushroom pigment: isolation and characterization. J Am Chem Soc 116: 88498850.

Tao, N., Orlando, M., Hyon, J.-S., Gross, M., and Song, P.-S. (1993) A new photoreceptor molecule from Stentor coeruleus. J Am Chem Soc 115: 2526-2528.

Toossi, Z., Farahbakhsh, Z.T., Hideg, K., and Hubbell, W. L (1993) Photoactivated conformational changes in rhodopsin: a time-resolved spin label study. Science 262: 14161419.

Tsuda, M., Nelson, B., Chang, C.-H., Govindjee, R., Ebrey, T.G. (1985) Characterization of the chromophore of the third rhodopsin-like pigment of Halobacterium halobium and its photoproduct. Biophys J 47: 721-724.

Van Beeumen, J., Devreese, B., Van Bun, S., Hoff, W.D., Hellingwerf, K.J., Meyer, T.E., McRee, D.E., and Cusanovich, M.A. (1993) The primary structure of a photoactive yellow protein from the phototrophic bacterium Ectothiorhodospira halophila, with evidence for the mass and the binding site of the chromophore. Protein Sci 2: 11141125.

Van Brederode, M.E., Gensch, Th., Hoff, W.D., Hellingwerf, K.J., and Braslavsky, S.E. (1995) Photoinduced volume changes and energy storage associated with the early transformations of the photoactive yellow protein. Biophys J 68: 1101-1109.

Van Brederode, M.E., Hoff, W.D., Van Stokkum, I.H.M., Groot, M.-L., and Hellingwerf, K.J. (1996) Protein folding thermodynamics applied to the photocycle of photoactive yellow protein. Biophys $J$ 71: 365-380.

Ward, M.J., Bell, A.W., Hamblin, P.A., Packer, H.L., and Armitage, J.P. (1995) Identification of a chemotaxis operon with two cheY genes in Rhodobacter sphaeroides. Mol Microbiol 17: 357-366.

Welch, M., Oosawa, K., Aizawa, S.-I., and Eisenbach, M. (1994) Effects of phosphorylation, $\mathrm{Mg}^{2+}$, and conformation of the chemotaxis protein $\mathrm{CheY}$ on its binding to the flagellar switch protein FliM. Biochemistry 33: 1047010476.

Wells, T.A., Nakazawa, M.A., Manabe, K., and Song, P.-S. (1994) A conformational change associated with the 
phototransformation of Pisum phytochrome A as probed by fluorescence quenching. Biochemistry 33: 708-712.

Yamamoto, K.T. (1993) Photoreversible change in the conformation of phytochrome as probed with a covalently bound fluorescent sulfhydryl reagent, $N$-(9-acridinyl)maleimide. Biochim Biophys Acta 1163: 227-233.

Yan, B., Takahashi, T., Johnson, R., Derguini, F., Nakanishi, K., and Spudich, J.L. (1990) All-trans/13-cis isomerization of retinal is required for phototaxis signaling by sensory rhodopsins in Halobacterium halobium. Biophys J 57: 807-810.

Yan, B., Nakanishi, K., and Spudich, J.L. (1991a) Mechanism of activation of sensory rhodopsin I: evidence for a steric trigger. Proc Natl Acad Sci USA 88: 9412-9416.
Yan, B., Takahasi, T., Johnson, R., and Spudich, J.L. (1991b) Identification of signaling states of a sensory receptor by modulation of lifetimes of stimulus-induced conformations: the case of sensory rhodopsin II. Biochemistry 30: 1068610692.

Yan, B., Xie, A., Nienhaus, G.U., Katsuta, Y., and Spudich, J.L. (1993) Steric constraints in the retinal binding pocket of sensory rhodopsin I. Biochemistry 32: 1022410232.

Yan, B., Spudich, J.L., Mazur, P., Vunnam, S., Derguini, F., and Nakanishi, K. (1995) Spectral tuning in bacteriorhodopsin in the absence of counterion and coplanarization effects. J Biol Chem 270: 29668-29670. 